\title{
Preparation and Characterization of Cellulose Nanofibril Films from Wood Fibre and Their Thermoplastic Polycarbonate Composites
}

\author{
S. Panthapulakkal and M. Sain \\ Centre for Biocomposites and Biomaterials Processing, Faculty of Forestry, University of Toronto, Toronto, ON, Canada M5S3B3 \\ Correspondence should be addressed to S. Panthapulakkal, s.panthapulakkal@utoronto.ca
}

Received 4 August 2011; Accepted 29 September 2011

Academic Editor: Peng He

Copyright (c) 2012 S. Panthapulakkal and M. Sain. This is an open access article distributed under the Creative Commons Attribution License, which permits unrestricted use, distribution, and reproduction in any medium, provided the original work is properly cited.

The aim of this study was to develop cellulose-nanofibril-film-reinforced polycarbonate composites by compression molding. Nano fibres were prepared from wood pulp fibres by mechanical defibrillation, and diameter distribution of the fibres produced was in the range of $1-100 \mathrm{~nm}$. Nanofibre films were prepared from the nanofibre suspensions and were characterized in terms of strength properties, crystallinity, and thermal properties. Strength and modulus of the nano fibre films prepared were $240 \mathrm{MPa}$ and $11 \mathrm{GPa}$, respectively. Thermal properties of the sheets demonstrated the suitability of processing fibre sheets at high temperature. Tensile properties of the films subjected to composite-processing conditions demonstrated the thermal stability of the fibre films during the compression molding process. Nanocomposites of different fibre loads were prepared by press-molding nano fibre sheets with different thickness in between polycarbonate sheet at $205^{\circ} \mathrm{C}$ under pressure. The tensile modulus and strength of the polycarbonate increased with the incorporation of the fibres. The strength of the thermoplastic increased $24 \%$ with $10 \%$ of the fibres and is increased up to $30 \%$ with $18 \%$ of the fibres. Tensile modulus of the polycarbonate demonstrated significant enhancement (about 100\%).

\section{Introduction}

Cellulose is the most abundant polymer in nature and is composed of linear polymer chains of $\beta$-1,4-linked glucose residues, and plant biomass is the richest resource for cellulose [1-3]. Utilization of the cellulose in composites is mainly to exploit its high strength and Young's modulus originated from the crystalline nature of the cellulose molecules, which in turn results from the hydrogen bonds extended along the molecular chains [2]. Many researchers reported the generation of nanocellulose or cellulose microfibrils from various resources and their application in the composite science and engineering [3-27]. The exploitation of cellulosic fibres as reinforcements in the composites has started more than a decade ago [4]. The principal reasons for the utilization of cellulosic fibrils are (i) its high specific strength and modulus compared to other engineering materials $[2,4]$ and (ii) its reinforcing potential [5]. The main challenge associated with the preparation of nanocellulose composite is their poor dispersion in the polymer matrix due to the agglomeration of the fibrils resulting from the hydrogen bonding within the cellulose fibrils. Most of the reported works used hydrophilic polymers to improve the dispersion, and plenty of research is going on in this direction to improve the dispersion and exploit the full potential of the nanocellulose [14-25]. A few attempts on the utilization of these cellulosic fibrils with hydrophobic thermoplastics were reported $[4,26,27]$.

Our research target is to develop high-performance materials using the high-strength micro- and nanocellulosic fibres for industrial applications. Wood cell walls consist of aggregates of 3-4 nm wide cellulose micro/nano fibrils [3], and these fibrils are embedded as a multilayered structure in hemicellulose and lignin network. Generation of nanofibrils from this cell wall network requires chemical and/or mechanical treatment. Many methods of separation have been reported so far including chemical treatment to 
generate holocellulose and further mechanical shearing either through cryocrushing, homogenization using highpressure homogenizer, microfluidizer, and/or grinder, ultrasonication, and wet milling $[4,7,9,11-13,28,29]$. In this paper, we are presenting the results of the wood-fibre-based cellulose microfibrils and their films in developing thermoplastic composite with polycarbonate sheets. We have used a commercial grinder with specially defined stones to generate micro- and nano fibrils. Nanosized cellulosic fibres were individualized from the pulp fibres by the shearing forces generated by the grinding stones. Commercially available wood pulp fibres used for this study were directly subjected to a grinder treatment to generate nanofibers. Composites were prepared using compression molding technique with the nano fiber films and polycarbonate sheets and were characterized.

\section{Experimental}

2.1. Materials. Fibres used for preparation of nanofibres and films were bleached kraft pulp fibres from Domtar, Canada. Polycarbonate film used in this study was from McmasterCarr, ON, Canada.

2.2. Preparation of Nanofibre Films. The wood pulp fibres were defibrillated using a nanofibre facility at the University of Toronto to generate nanofibre suspensions. The fibers were made into a $2 \%$ suspension in water and defibrillated by passing through a commercial grinder (Masuko Corp., Japan). After defibrillation, appropriate amount of the suspension was diluted with water and vacuum-filtered using a membrane filter to produce a thin film of thickness approximately 50 microns. The films were then pressed to remove water under pressure for 15 minutes and then dried at $40^{\circ} \mathrm{C}$ for $48 \mathrm{~h}$. The films were cut using ASTM dre Type E and then dried at $100^{\circ} \mathrm{C}$ for $2 \mathrm{~h}$ to ensure complete drying. The thickness of the samples was measured as an average of 5point measurements in the tensile specimen.

\subsection{Characterization of Fibres and Films}

2.3.1. Microscopic Study and Diameter Distribution. Scanning electron microscopy (microscope model Hitachi S2500) was used to examine the microstructure of wood fibres before processing into nanofibres. Prior to SEM examination, the samples were sputter-coated with a thin layer of gold to avoid electrostatic charge during examination. Transmission electron microscopy (TEM) was used to study the fibre diameter distribution of nanofibres generated. A drop of dilute nanofibre suspension was deposited on the carbon coated grids and allowed to dry before the analysis. Fibre diameter was measured with the help of an image processing analysis program called UTHSCA Image tool down-loaded from http://ddsdx.uthscsa.edu/dig/itdesc.html. The images from scanning electron microscopy and transmission electron microscopy were loaded into the software package and analyzed. The scale of the software was calibrated using the scale bars on each SEM and TEM images. The diameter of
200 fibres from each sample was measured and recorded to get the diameter distribution of the fibres.

2.3.2. X-Ray Diffraction and Crystallographic Study. The crystallinity of the cellulose fibre films before and after defibrillation was examined using a Bruker AXS D8 Discovery Diffraction System, and the method was explained elsewhere [11].

2.4. Preparation of Nanofibre-Polycarbonate Composite Film. Nanocellulose-polycarbonate composite films were prepared by compression molding method. The nano film was placed in between the polycarbonate sheet and pressed in between the steel plates at a temperature of $210^{\circ} \mathrm{C}$ under a pressure of $1 \mathrm{MPa}$ for 1 minute and then under a load of 5 tons for $30 \mathrm{sec}-$ onds. The composite was cooled to ambient temperature under pressure and left under atmospheric conditions for $24 \mathrm{~h}$ before testing. The nano films used for making composites were surface-treated with isocyanate-based polymers, and the composites contain about $1.5 \mathrm{wt} \%$ of the surface modifier.

2.5. Mechanical Properties of the Cellulose Films and Composite. Tensile properties of the nanofibre film and the nanofiber-polycarbonate composites were measured at room temperature using ASTM type E tensile specimens. A standard computerized testing machine (Instron Model 20) was used in accordance with the ASTM D-638 procedure with a load cell of $10 \mathrm{kN}$ and a cross head speed of $2.5 \mathrm{~mm} / \mathrm{min}$. At least five sample specimens for each set were tested to get the average value.

\section{Results and Discussion}

3.1. Microscopic Studies and Diameter Distribution. A typical scanning electron micrograph and transmission electron micrograph of wood pulp fibres and nanofibres are shown in Figures 1 and 2. The mechanical grinding of the fibers resulted in defibrillation of cellulose fibrils from the cell walls as is evidenced from the diameters of the fibres. The average fibre width of wood fibres is considerably decreased after mechanical defibrillation. The fibre diameter distribution of the wood pulp fibres before and after mechanical defibrillation was calculated from the SEM and TEM images using the image processing analysis program, UTHSCSA Image tool, and is shown in Figure 3. It is clear from the figure that the size of the fibers decreases from microns to nanofibre levels after defibrillation. Diameter distribution of wood fibres shows that almost $90 \%$ of the fibres were distributed in the diameter range of 10-40 microns and is accounted for an average diameter of 22 microns with a standard deviation of 9 microns. It is evident that almost $90 \%$ of the wood nanofibres generated after shearing by the grinding action is distributed in the range of $1-100 \mathrm{~nm}$ with more than $60 \%$ of the fibres with a diameter in the range of 1-60 $\mathrm{nm}$ and lengths of several thousand nanometers.

3.2. Crystallinity of the Cellulose Films. Crystallinity of cellulose microfibrils arises from the hydrogen bonds between 


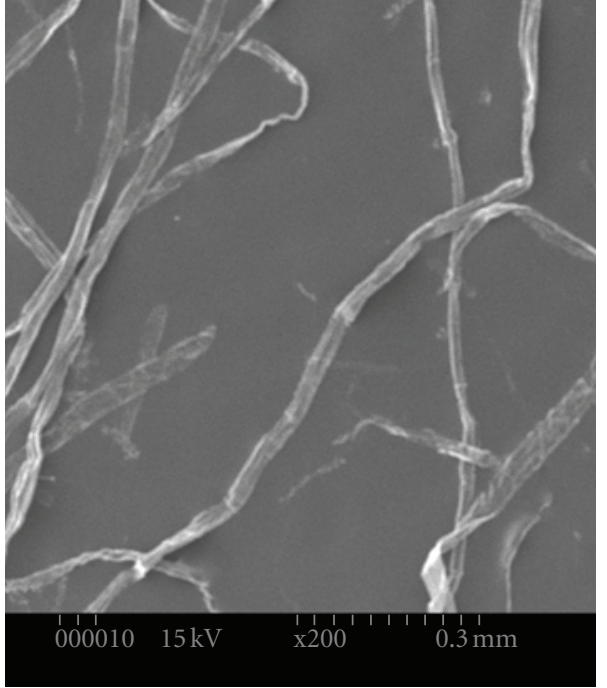

FIgURE 1: Scanning electron micrograph (SEM) of wood fibre.

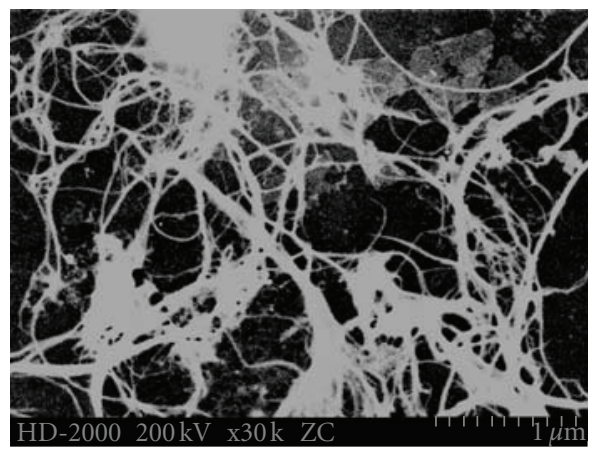

FIgURE 2: Transmission electron micrograph (TEM) of wood nanofibrils.

cellulose molecules and the resulted conformation of the cellulose molecules. It is reported that the length of crystallites in native cellulose can be $100-250 \mathrm{~nm}$ with cross-section of $3-10 \mathrm{~nm}$. In plant cell walls it is believed that the cellulose crystallites are interconnected to each other by disordered cellulose molecules and hemicellulose and associated lignin network. The crystallinity of the cellulosic fibres highly depends on the source and the degree of degradation of the fibres during chemical and physical method used for the separation of the fibrils from the plant cell wall $[30,31]$.

XRD pattern of wood pulp fibre sheet and nanofibre sheet is shown in Figure 4. Cellulose I is the common variety found in the plants and is characterized by the well-defined principal peak at $22.5(2 \theta)$ and the two overlapping secondary peaks at 14.5 and $16.3(2 \theta)$, which are associated with crystalline planes of $101,1 \overline{0} 1$ and 002 . No rearrangement of the cellulose structure into another crystalline form was observed upon defibrillation of the pulp fibres indicating that the method of grinding affects the amorphous region more than the crystalline region. A similar study was reported in the wet-stirred media milling of wood pulp fibres [29].
Methods for quantifying crystallinity from XRD have been proposed either by using the areas under the peaks or the heights of the maxima and minima of the curve above the base line $[31,32]$. In this paper we used the method of minima and maxima for the calculation of crystallinity index and crystallinity ratio, which is the two ways of expressing crystallinity of cellulose and are calculated using the following equations:

$$
\begin{gathered}
\text { crystallinity index (C.I.) }=\frac{\left(I_{\max }-I_{\min }\right)}{I_{\max }}, \\
\text { crystallinity ratio (C.R.) }=1-\left[\frac{I_{\min }}{\left(I_{\max }-I_{\min }\right)}\right],
\end{gathered}
$$

where $I_{\max }$ is the height of the $22.5^{0}(2 \theta)$ peak above the base line and $I_{\min }$ is the height of the $19^{\circ}(2 \theta)$ minimum above the base line. The crystallinity index and the crystallinity ratios calculated using the above equations are similar, and the C.I. and C.R. values of wood fibre paper are 0.86 and 0.84 , while those of nanofibre are 0.90 and 0.89 , respectively. The crystallinity index values of wood and nanofibres were comparable to each other indicating that crystallinity is not affected by the mechanical process for the generation of nanofibres. The high crystallinity index values of the fibre sheets show the crystalline nature of the cellulosic papers and are expected to have high strength for these cellulose papers.

3.3. Thermal Properties. The aim of this study was to process the nanofibre sheets from wood fibres with thermoplastics under temperature and pressure to make composites. In this context, thermogravimetric analysis of the wood fibre sheets was studied to understand the degradation characteristics of these sheets. The TGA curves of the wood fibre sheets and nanofibre sheets are shown in Figure 5. It is clear from the figure that the onset of degradation of both fibre sheets is well above $200^{\circ} \mathrm{C}$, and the higher onset of degradation temperature indicates the improved thermal stability of the fibers compared to the lignocellulosic fibres. This enhanced stability may be due to the absence of lignin and hemicelluloses compared to the natural fibres, and this indicates the suitability of these fibers for processing with thermoplastics, even with high melting polymers. Further, in order to verify if there is any thermal degradation of the fibres occurring during processing of the composites, the nanofibre films were subjected to high temperature $\left(185-225^{\circ} \mathrm{C}\right)$ and pressure similar to the processing conditions of composites. Tensile properties of the heat-treated samples were compared with those of the original fibre sheets. The results of the tensile strength and modulus values are shown in Figure 6. The nanofibre sheets retained its strength and modulus under the conditions of composite processing (about $200^{\circ} \mathrm{C}, 2 \mathrm{~min}$ ) and under pressure, and it is noticed that above $225^{\circ} \mathrm{C}$ the strength properties decreased marginally compared to the processing conditions used for composite preparation. This indicates that the hot pressing conditions used in this study do not have any adverse effect on the strength of the films in the composites prepared. 


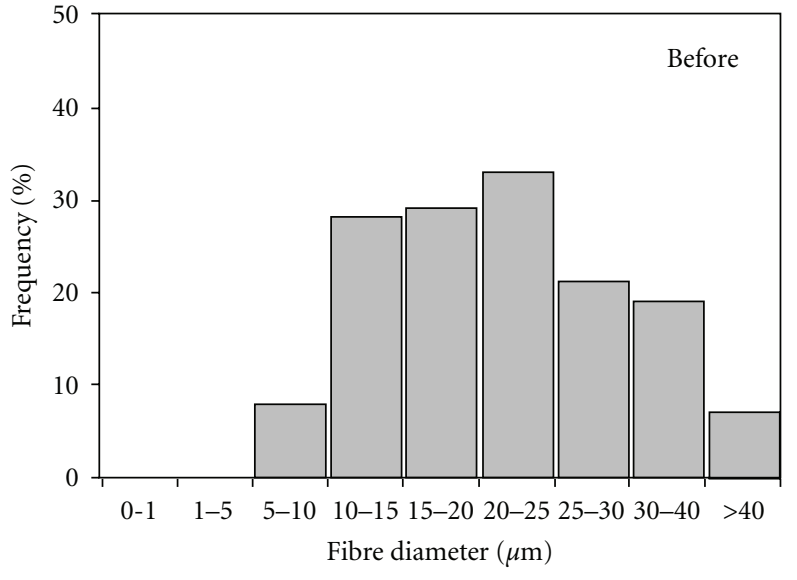

(a)

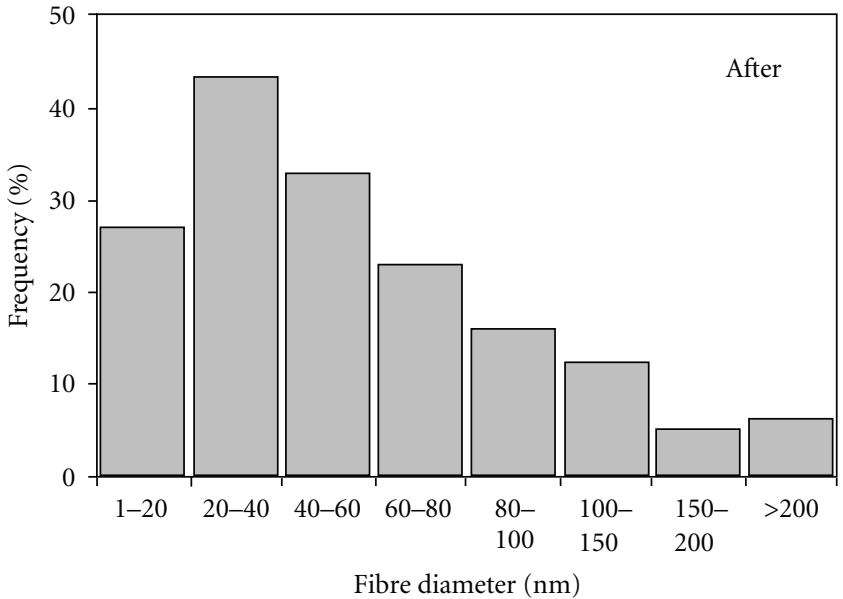

(b)

FIgURE 3: Diameter distribution of fibres before and after defibrillation.

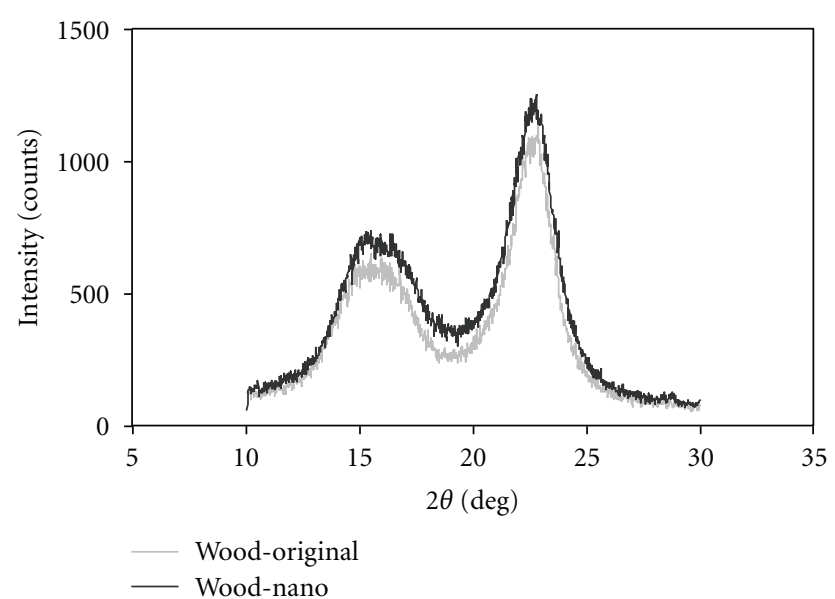

FIGURE 4: XRD of wood fibres before and after defibrillation.

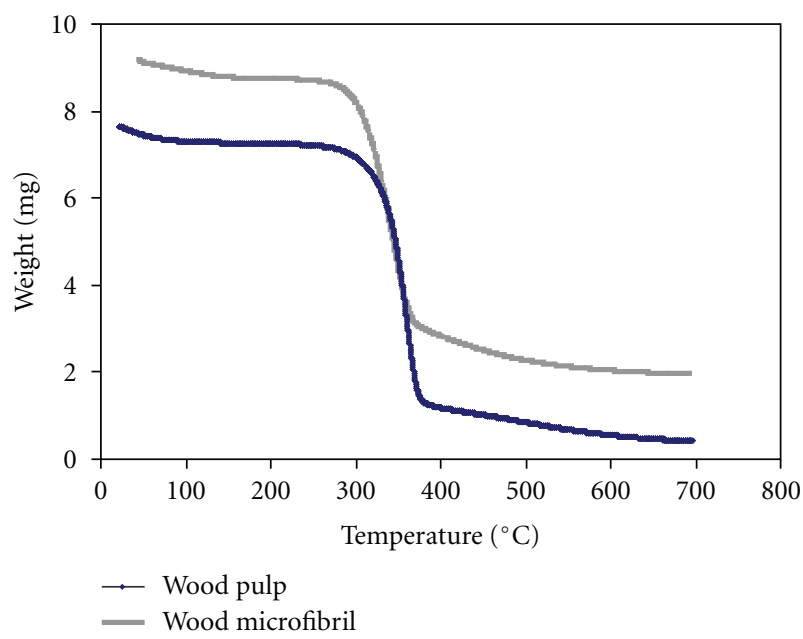

FIGURE 5: TGA thermograms of wood fibres before and after defibrillation.

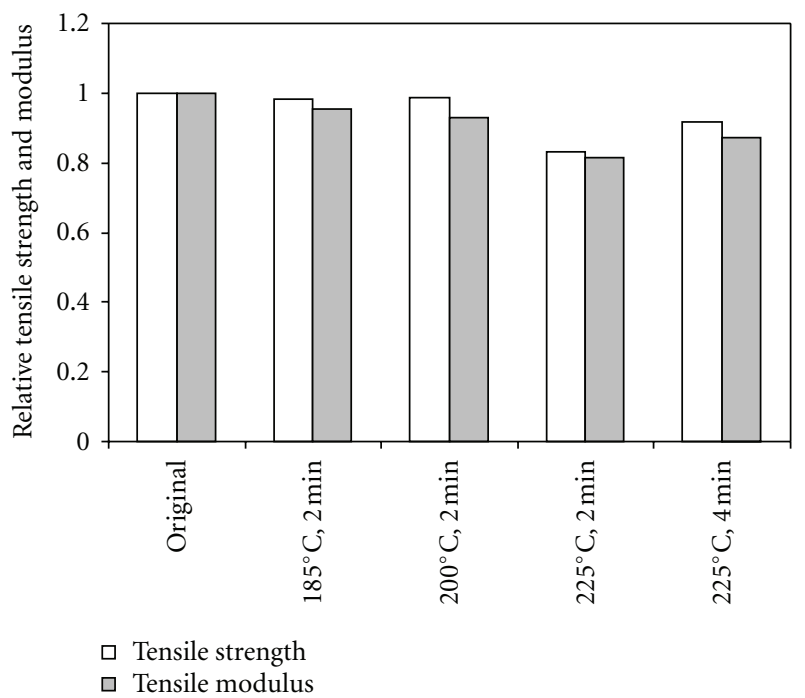

FIGURE 6: Retention of tensile properties of nanofilms subjected to different processing conditions.

3.4. Tensile Properties of the Composites. Tensile properties of the nanofiber films prepared were determined, and the average strength and modulus of the films were found to be $240 \mathrm{MPa} \pm 12 \mathrm{MPa}$ and $11 \mathrm{GPa} \pm 0.6 \mathrm{GPa}$, respectively. Composites were prepared by compression molding, by placing the nano sheets in between polycarbonate sheets, under pressure and temperature. Different fibre loads of the fibres in the composites were achieved by preparing the nano sheets with different thickness. Figure 7 shows the tensile strength and modulus of the polycarbonate sheet and the wood nanofibre-polycarbonate composites with different fibre loads (varies from 10 to $32 \mathrm{wt} \%$ ). The figure indicates that the strength and modulus of the polycarbonate sheets increased with the incorporation of the nanofibres. The tensile strength of the composites increases up to $20 \%$ of the fibre content and then remains the same at about $28 \%$ of fibre content 


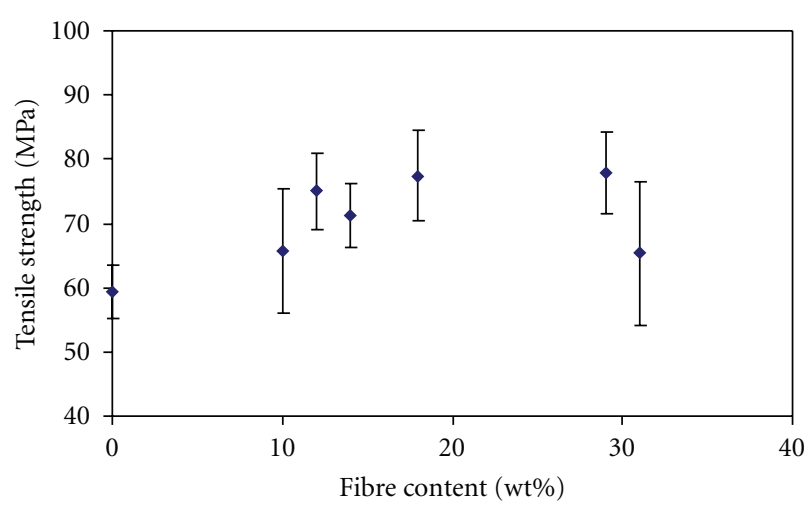

(a)

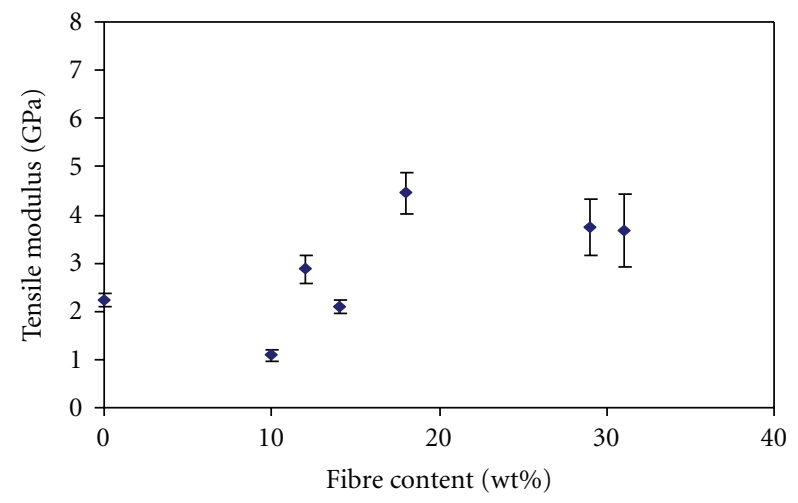

(b)

FIgURE 7: (a) Tensile strength of composites, (b) tensile modulus of composites.

and then showed a reverse trend. This may be due to the poor wetting of the fibres with the polycarbonate as a result of the increased surface area of the fibres. The percentage in the strength of the matrix is increased from $26 \%$ to $30 \%$ by incorporating a fibre loading of $11 \mathrm{wt} \%$ to $18 \mathrm{wt} \%$. There is a significant increase in the modulus of the composites compared to the strength. Modulus of the polycarbonate sheets increases about $100 \%$ by using about $12 \mathrm{wt} \%$ of the nanofibrillated sheets. Unlike modulus, ultimate strength of the composite is influenced by the flaws present in the composite, and this could arise from different sources such as poor adhesion between the nano sheet and the polymer and nonuniformity in the thickness of the sheets. This will be investigated as a part of the further research in this direction. The results from this study indicate that reinforcing ability of the hydrophilic cellulosic fibres can be exploited for reinforcing hydrophobic thermoplastics to develop composites with improved properties.

\section{Conclusions}

Cellulose nano fibrils were prepared by mechanical defibrillation of wood pulp fibres using a commercial grinder, and sheets were prepared by vacuum filtration of the dilute solutions of the fibre suspensions. The fibre films were characterized in terms of strength, crystallinity, and thermal properties. Strength and modulus of the nanofibre film were considerably high and were found to be $240 \mathrm{MPa}$ and $11 \mathrm{GPa}$, respectively. Crystallinity studies showed that there is no degradation in the crystallinity of the pulp fibres during mechanical grinding process. Thermal properties of the fibre sheets showed their suitability of processing with polymers with thermoplastics, and the retention of the strength and modulus demonstrated that the processing conditions used in this study for making composites do not have an adverse effect on the properties of the sheets.

Cellulose nanocomposite processing via compression molding of nanocellulose sheets with polycarbonate was attempted. Evaluation of the strength properties of the polycarbonate and its composites showed a trend that demonstrated an improvement in the tensile strength and modulus with nanofibre reinforcement. The modulus of the PC improves about $100 \%$ by incorporating about $18 \%$ of the nanofibres, and an increase of $30 \%$ is observed in the tensile strength for the composite with the same fibre content.

The study was a preliminary attempt to develop nanofibre-reinforced thermoplastic composites with improved properties, and the results demonstrated the reinforcing ability of the cellulosic nano fibrils for reinforcing the hydrophobic thermoplastic composites. The detailed study of the composites, such as microstructural evaluation, interaction between the nano fibrils and polymer matrix, and effect of surface treatment on the wetting properties of the composites, would be the subjects of future studies.

\section{Acknowledgment}

The authors would like to acknowledge the financial support from the Natural Fibres for the Green Economy Network (NAFGEN) for this research.

\section{References}

[1] F. A. L. Clowes and B. E. Juniper, Plant Cells, Blackwell Scientific Publications, Oxford, UK, 1968.

[2] K. Tashiro and M. Kobayashi, "Theoretical evaluation of threedimensional elastic constants of native and regenerated celluloses: role of hydrogen bonds," Polymer, vol. 32, no. 8, pp. 1516-1526, 1991.

[3] A. J. Stamm, Wood and Cellulose Science, Ronald, New York, NY, USA, 1964.

[4] S. J. Eichhorn, A. Dufresne, M. Aranguren et al., "Review: current international research into cellulose nanofibres and nanocomposites," Journal of Materials Science, vol. 45, no. 1, pp. 1-33, 2010.

[5] L. A. Berglund, "Cellulose-based nanocomposites," in Natural Fibers, Biopolymers, and Biocomposites, A. K. Mohanty, M. Misra, and L. T. Drzal, Eds., pp. 807-832, CRC Press, Boca Raton, Fla, USA, 2005

[6] A. F. Turbak, F. W. Snyder, and K. R. Sandberg, "Microfibrillated cellulose, a new celluloseproduct: properties, uses, and commercial potential," Journal of Applied Polymer Science. Applied Polymer Symposium, vol. 37, pp. 815-823, 1983. 
[7] A. Chakraborty, M. Sain, and M. Kortschot, "Cellulose microfibrils: a novel method of preparation using high shear refining and cryocrushing," Holzforschung, vol. 59, no. 1, pp. 102-107, 2005.

[8] T. Zimmermann, E. Pöhler, and T. Geiger, "Cellulose fibrils for polymer reinforcement," Advanced Engineering Materials, vol. 6, no. 9, pp. 754-761, 2004.

[9] T. Taniguchi and K. Okamura, "New films produced from microfibrillated natural fibres," Polymer International, vol. 47, no. 3, pp. 291-294, 1998.

[10] K. Abe, S. Iwamoto, and H. Yano, "Obtaining cellulose nanofibers with a uniform width of $15 \mathrm{~nm}$ from wood," Biomacromolecules, vol. 8, no. 10, pp. 3276-3278, 2007.

[11] A. Alemdar and M. Sain, "Isolation and characterization of nanofibers from agricultural residues-wheat straw and soy hulls," Bioresource Technology, vol. 99, no. 6, pp. 1664-1671, 2008.

[12] J. Sreekumar and M. Sain, "Isolation of cellulose microfibrils_-an enzymatic approach," BioResources, vol. 1, no. 1, pp. $1-5,2006$.

[13] H. P. Zhao, X. Q. Feng, and H. Gao, "Ultrasonic technique for extracting nanofibers from nature materials," Applied Physics Letters, vol. 90, no. 7, Article ID 073112, 2 pages, 2007.

[14] M. N. Anglès and A. Dufresne, "Plasticized starch/tunicin whiskers nanocomposite materials. 2: mechanical behavior," Macromolecules, vol. 34, no. 9, pp. 2921-2931, 2001.

[15] A. Bhatnagar and M. Sain, "Processing of cellulose nanofiberreinforced composites," Journal of Reinforced Plastics and Composites, vol. 24, no. 12, pp. 1259-1268, 2005.

[16] A. P. Mathew, K. Oksman, and M. Sain, "Mechanical properties of biodegradable composites from poly lactic acid (PLA) and microcrystalline cellulose (MCC)," Journal of Applied Polymer Science, vol. 97, no. 5, pp. 2014-2025, 2005.

[17] A. N. Nakagaito, S. Iwamoto, and H. Yano, "Bacterial cellulose: the ultimate nano-scalar cellulose morphology for the production of high-strength composites," Applied Physics A, vol. 80, no. 1, pp. 93-97, 2005.

[18] M. E. Malainine, M. Mahrouz, and A. Dufresne, "Thermoplastic nanocomposites based on cellulose microfibrils from Opuntia ficus-indica parenchyma cell," Composites Science and Technology, vol. 65, no. 10, pp. 1520-1526, 2005.

[19] M. Nogi and H. Yano, "Transparent nanocomposites based on cellulose produced by bacteria offer potential innovation in electronics device industry," Advanced Materials, vol. 20, pp. 1849-1852, 2008.

[20] A. Chakraborty, M. Sain, and M. Kortschot, "Reinforcing potential of wood pulp-derived microfibres in a PVA matrix," Holzforschung, vol. 60, no. 1, pp. 53-58, 2006.

[21] K. Oksman, A. P. Mathew, D. Bondeson, and I. Kvien, "Manufacturing process of cellulose whiskers/polylactic acid nanocomposites," Composites Science and Technology, vol. 66, no. 15, pp. 2776-2784, 2006.

[22] S. Iwamoto, A. N. Nakagaito, and H. Yano, "Nano-fibrillation of pulp fibers for the processing of transparent nanocomposites," Applied Physics A, vol. 89, no. 2, pp. 461-466, 2007.

[23] A. Iwatake, M. Nogi, and H. Yano, "Cellulose nanofiberreinforced polylactic acid," Composites Science and Technology, vol. 68, no. 9, pp. 2103-2106, 2008.

[24] J. Lu, T. Wang, and L. T. Drzal, "Preparation and properties of microfibrillated cellulose polyvinyl alcohol composite materials," Composites Part A, vol. 39, no. 5, pp. 738-746, 2008.

[25] S. F. Souza, A. L. Leão, J. H. Cai, C. Wu, M. Sain, and B. M. Cherian, "Nanocellulose from curava fibers and their nanocomposites," Molecular Crystals and Liquid Crystals, vol. 522, pp. 42-52, 2010.
[26] B. Wang and M. Sain, "Isolation of nanofibers from soybean source and their reinforcing capability on synthetic polymers," Composites Science and Technology, vol. 67, no. 11-12, pp. 2521-2527, 2007.

[27] M. A. S. Azizi Samir, F. Alloin, J. Y. Sanchez, and A. Dufresne, "Cellulose nanocrystals reinforced poly(oxyethylene)," Polymer, vol. 45, no. 12, pp. 4149-4157, 2004.

[28] A. Bhatnagar, Isolation of cellulose nanofibres from renewable feed stocks and root crops, M.S. thesis, 2004.

[29] H. Liimatainena, J. Sirviö, A. Haapalaa, O. Hormib, and J. Niinimäkia, "Characterization of highly accessible cellulose microfibers generated by wet stirred media milling," Carbohydrate Polymers, vol. 83, pp. 2005-2010, 2011.

[30] J. Blackwell, "Effect of treatments involving microstructure (of cellulose)," in Cellulose and Cellulose Derivatives, N. M. Bikales and L. Segal, Eds., vol. 5, pp. 39-50, Wiley-Interscience, New York, NY, USA, 1971.

[31] H. A. Foner and N. Adan, "The characterization of papers by X-Ray diffraction (XRD): measurement of cellulose crystallinity and determination of mineral composition," Journal of the Forensic Science Society, vol. 23, no. 4, pp. 313-321, 1983.

[32] L. Segal, J. J. Creely, A. E. Martin Jr., and C. M. Conrad, "An empirical method for estimating the degree of crystallinity of native cellulose using X-Ray diffractometer," Textile Research Journal, vol. 17, pp. 585-596, 1947. 

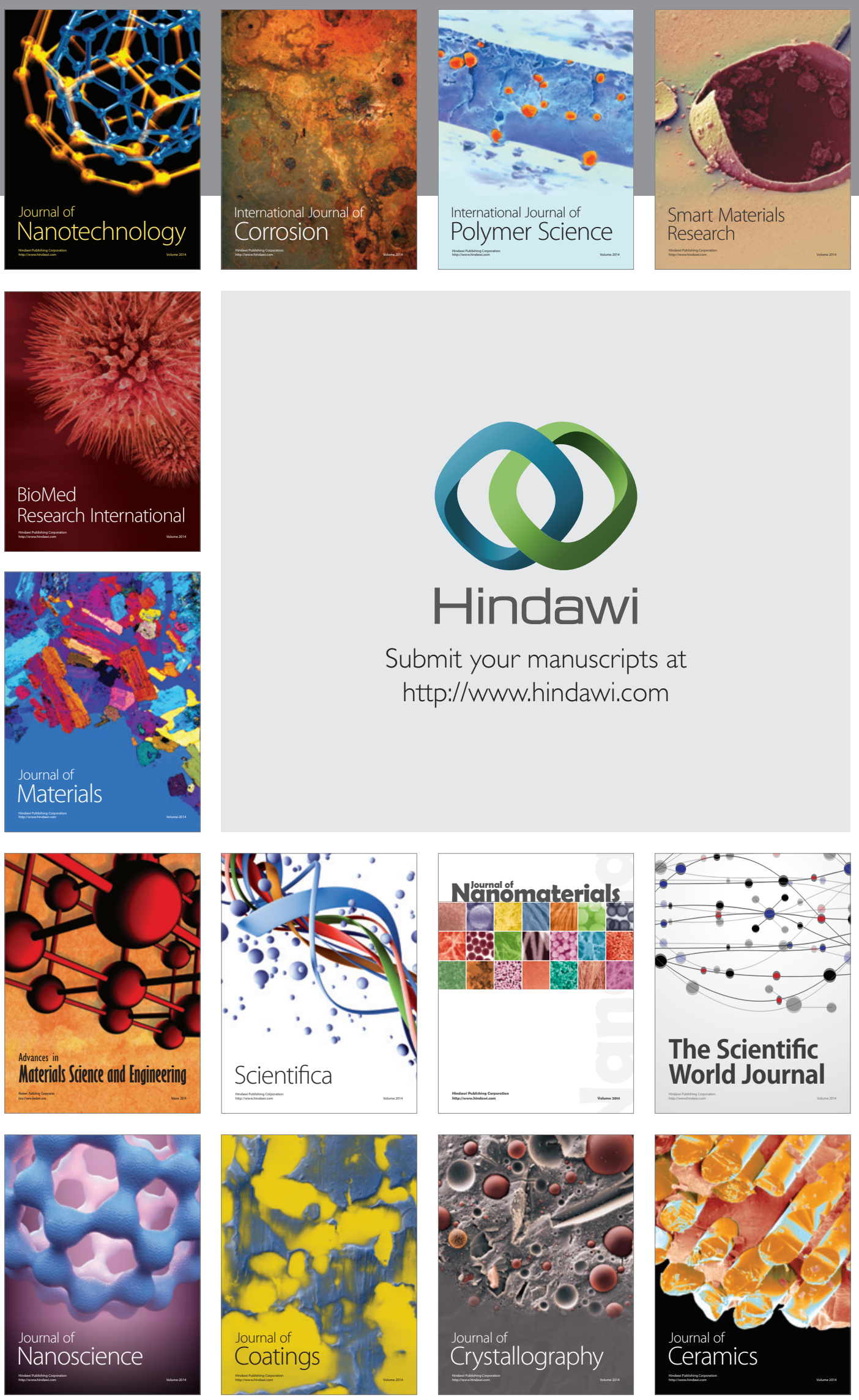

The Scientific World Journal

Submit your manuscripts at

http://www.hindawi.com

\section{World Journal}

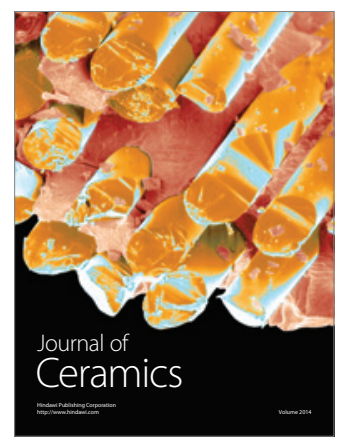

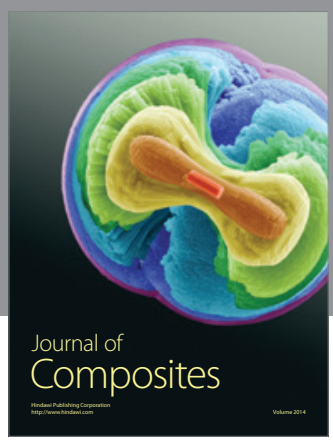
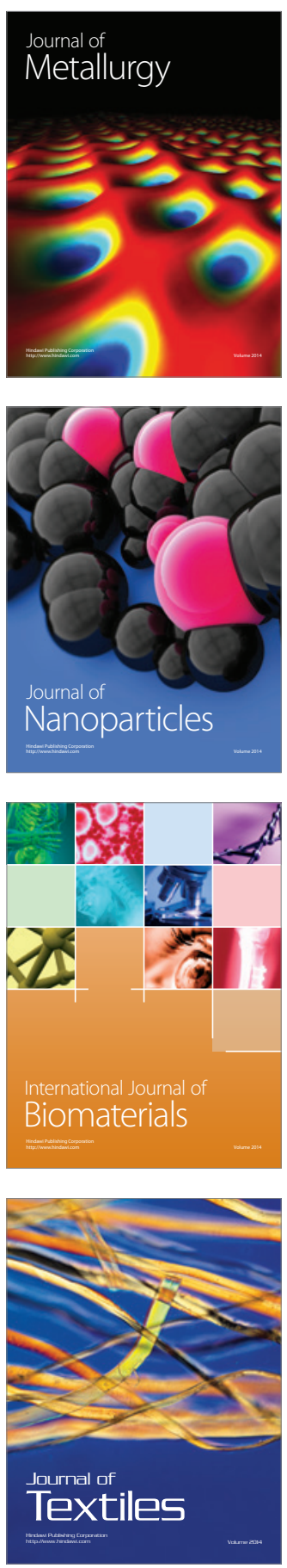